\title{
Hybrid accountabilities and managerial agency in the third sector
}

\author{
ABSTRACT \\ This paper investigates how the dynamics of conflicting accountabilities are managed within \\ the context of the third sector; specifically in organizations providing services for people with \\ learning difficulties. Multiple accountability relationships create organizational settings that \\ are subject to multiple constraints and risks but also offer resources for agency. We analyse \\ how managers take up agency to enable them to enact, resist or reconcile multiple \\ accountabilities. Our study's contribution lies in our elucidation of the far-reaching hybridity \\ of the third sector and the complex forms of actorhood it cultivates, in which managers are \\ able to handle resources with great dexterity, in pursuit of settlements which may only be \\ contingent and temporary.
}

KEYWORDS: hybridity, accountabilities, agency, ordinary life, services for people with learning difficulties

\section{INTRODUCTION}

In the UK third sector, 'intense organizational hybridity' (Billis 2010, p. 46) is a long established, rather than new, situation. 'Third sector' is the term increasingly used to differentiate those organizations located in the space between market and state, that are formally constituted, independent of government (though in many cases receiving government funding), non-profit making, and established to further some social purpose (Schwabenland 2016). These organizations are located at the nexus of multiple, dynamic, 'polycentric' (Black 2008) accountability relationships: as independently constituted organizations, executive staff are legally accountable to the governing board of trustees. 
These may or may not be comprised of the principal beneficiaries, or users of its services, to whom the organization is also accountable. Those staff who are professionally qualified (for instance as social workers or nurses) are also accountable for the standards of good practice established by professional associations, alongside ever-evolving ideas about how such good practice should be enacted. Service providing organizations are further accountable to regulatory bodies. Furthermore, as a consequence of the marketization of the public sector (Pollitt and Bouckaert 2011), services that were originally funded through open-ended grants are increasingly likely to be commissioned via tightly specified service contracts that require the organization that has 'won' a tender to be legally accountable for contract compliance to the public commissioning bodies. In totality, these accountability relationships are both mandatory (required by law) and self-imposed (not required by legislation and directed towards societal rather than state actors) (Koop 2014). In Mulgan's (2000) terms these accountabilities are both 'core' (in the sense that accountability is external, it involves social interaction and exchange, and implies rights of authority) and 'expanded' (ie based on an internal sense of personal responsibility for the conscientious performance of duties to fellow professionals and to wider publics). The third sector is therefore a promising site for investigating the dynamics of accountability relationships because it is at the sharp end of the growing complexity of the accountability environment evident across public service provision (Benish and Levi-Faur 2012).

Bovens (2007) defines the character of the accountability relationship as that between an actor and a forum, whereby the actor 'has an obligation to explain and to justify his or her conduct, the forum can pose questions and pass judgments, and the actor may face consequences' (p. 450). Third sector organizations must maintain hybrid arrangements because their survival is reliant on satisfying the requirements of all the fora to which they 
are accountable (Brandsen et al 2005; Ebrahim et al 2014). Previous research has highlighted challenges inherent in such complex accountability regimes, including managing the tensions between demands of government stakeholders and beneficiaries (Ospina et al 2002), between business and social purposes (Sanders and McClellan 2012) and the danger of 'mission drift' (Meyer et al 2014).

Such challenges are not unique to third sector organizations and may be experienced, to greater or lesser extent, in any sector where there are tensions between values and market driven imperatives. However, we contend that for third sector organizations involved in providing services under contract these are existential challenges. For example, a report by the Third Sector Research Centre demonstrated that the ratio of funding received from commercial activities had increased significantly in relation to other, more flexible sources of funding in England and Wales: 'conclud[ing] that charities are succumbing to market' (McKay et al 2011: 2). Such concerns prompted the National Coalition for Independent Action to launch an enquiry into the independence of service providing organizations, arriving at the judgment that 'overall, the environment for service-providing voluntary organisations is increasingly difficult, hostile and getting worse: for the people for whom they provide services and undertake activities; for the scope and quality of the services they provide; and for their own independence and self-determination in these matters' (NCIA 2015:3)

Few studies have investigated how managers deploy agency to devise responses to such hybridity, both within the third sector (Skelcher and Smith 2015) and in wider public service or professional contexts (Denis et al 2015; Goodrick and Reay 2011). Binder's (2007) 
ethnographic study of a third sector housing association shows that managers of different organizational subunits enacted divergent responses in their attempts to satisfy multiple demands. Binder concludes that, as well as constraining action, accountability relationships also carry heterogeneous resources that actors use in interaction to mobilize agency. Writing from an institutional logics perspective, Skelcher and Smith (2015) specify a research agenda extending Binder's (2007) work by examining how logics are interpreted and deployed. Denis et al (2015) also call for research examining 'the agency and social interaction processes that shape $[\ldots]$ responses and consequently explore the hybridization process' (p. 285; italics original). This paper furthers understanding of the hybridization process by examining the choices managers make in enacting, reconciling or resisting competing accountability demands, and how they deploy agency in making these choices.

Conceptualizing agency is itself no easy task; several current streams of research do so in ways that variously take account of the plurality of institutional environments, using e.g. Critical Realism (Delbridge and Edwards 2013), Actor-Network Theory (Denis et al 2015), and institutional logics and actor identities (Skelcher and Smith 2015; Spyridonidis et al 2015; Meyer et al 2014; Reay et al 2018). Our analysis is based on Emirbayer and Mische's (1998) understanding of agency as the deployment of a set of resources deriving from past habits, competence at dealing with present exigencies and the ability to imagine various possible futures. As Emirbayer and Mische (1998) propose, and as Binder (2007) begins to illustrate, actors at the nexus of multiple accountability relationships are likely to be expert at dealing with complexity because they have built up extensive repertoires or 'action strategies' (Swidler 1986) and are themselves 'complexly structured' (Meyer and Jepperson 2000, p. 112) or 'modular' (Abdelnour et al 2017). 
Our study focuses on managers working in third sector organizations that provide services for people with learning difficulties ${ }^{1}$. In this field, for over 40 years, an influential form of internal accountability (Mulgan 2000) is to the belief that people with learning difficulties should be supported to live an 'ordinary life', in the community and alongside people without disabilities. Our data are drawn from an action research initiative, established by Transitions ${ }^{2}$, a UK-based training and development provider. The purpose of the action research was to help managers identify barriers to the provision of such 'ordinary' person-centred services and how they might be overcome. Managers raised the theme of competing demands from commissioners, families, employees, social workers and from the people they supported, both in the workshops that constituted the action research and in subsequent interviews. Their managerial positions placed them 'in situations where they have "no choice but to choose", (Kraatz and Block 2008, p. 263) and it these choices we examine.

We begin with a more detailed account of research into hybrid accountability relevant to the third sector. We then set out the theoretical framework we use to analyse agency. Next, we describe our research design, including the significance of the commitment to an 'ordinary life' in this empirical setting. We present our analysis of the ways in which managers negotiated the multiple accountability demands they encountered in a variety of day-to-day situations and conclude by discussing the theoretical implications of our findings.

\section{THE THIRD SECTOR AS A SOURCE OF HYBRIDITY AND MULTIPLE}

\section{ACCOUNTABILITIES}

Billis's anthology on hybridity and third sector organizations (2010) identifies a paradox. On the one hand, the boundaries between the public and private sectors have become so blurred that there is little to differentiate them and concomitantly, less space between them in which 
an alternative third sector can be positioned. Yet, on the other hand, third 'sector identity remains powerful and important...provid[ing] a deep rooted and fundamentally different way of responding to problems' (p. 8). Thus, the perception of distinctiveness is a powerful imaginary that continues to have salience despite successive governments' attempts to instill market dynamics and rigours.

The 1993 report published by the Centris Foundation on Voluntary Action (Knight 1993) made an early analysis of this fundamental tension, predicting that public sector reforms would inexorably lead to a division between organizations providing services, which would become contractors of the state, and those concerned with advocacy, campaigning and grassroots development. Knight regarded this as inevitable because the service contract tendering regimes would increase competition between bidders and de-legitimize their roles as advocates for the people using their services. This outcome has been resisted, at least in principle, by subsequent generations of people working in the sector (Schwabenland 2016), but managers continue to experience conflicts in maintaining both areas of work.

Subsequent research has recognized that the tensions inherent in third sector organizing are not only dual, but polycentric (Black 2008). The number and complexity of accountability relationships practiced in the wider public sector has grown beyond what is required by law, and Koop (2014) suggests that such non-mandatory accountability may become salient if one or more of five conditions apply: where the issues the organization is working with are politically sensitive; where an organization regards itself as accountable to its beneficiaries as well as to its funders; where taxpayers' money is received; where its legal status may be unclear to external stakeholders; and if the organization is 'young' and has not had time to establish public trust. 
The potential conflicts facing the hybrid or 'pluralistic' organization lead Kraatz and Block (2008) to wonder that 'its mere ability to hang together [is] something of a mystery' (p. 257). Recent empirical studies of third sector organizations have explored how they do indeed hang together and satisfy the plural demands placed on them. Ebrahim (2003) notes that organizations may either 'alter their rhetoric to appease multiple principals or dogmatically affirm their own missions' (p.198); however, in a later study Ebrahim et al (2014) suggest that non-profits should rather maintain hybridity through finding an alignment between potentially conflicting objectives and interests to the overall mission. Ebrahim et al (2014) recognize that some stakeholders, whose claims constitute the purpose of the organization, typically have little voice, and so governing boards have a particular responsibility to manage the tension between 'upward' and 'downward' accountability. Castellas et al (2018) concur with Ebrahim et al (2014) that a 'critical success factor' is the 'ability to sustain pluralism' (p.14), commenting that 'when one value becomes the super value, the organization ceases to be a hybrid' (p. 14). However, as Sanders and McClellan (2014 p. 68) show, enduring tensions remain between 'being business-like while pursuing a social mission' and the associated conflicts of identity.

Skelcher and Smith's (2015) review of hybridity in third sector organizations proposes a variety of organizational responses to plural institutional logics. Functions oriented to different logics may be compartmentalized within the organization or segregated into separate organizations - as predicted by Knight (1993). Alternatively, they may be assimilated, blended synergistically or rejected, when competing demands are irresolvable. Skelcher and Smith (2015) specify a research agenda which examines how hybrid logics are handled within organizations and how settlements are reached. 
Although pre-dating the studies mentioned above, Binder's (2007) analysis of the responses of a housing project to a dramatic shift towards government funding extends understanding of the micro-processes by which such pluralism can be managed. Binder's study proceeds from the basis that institutions are 'inhabited' (Fine and Hallett 2014) by people who collectively make sense of institutional logics and make choices over how to deal with them. She shows that managers of different subunits treated logics differently and concludes that logics do not only operate on an 'outside-in' basis - or 'upward and downward' (Ospina et al 2002; Ebrahim et al 2014) - but their meaning is negotiated in interaction: hence, managers 'play with them, question them, combine them with logics from other domains, take what they can use from them and try to make them fit with their needs' (p.568).

Binder (2007) contributes by disassembling the organization into its subunits, a move which brings into view how responses are conditioned by different accountabilities, such as to funders and professional ideals. As she also acknowledges, but does not fully develop, individuals themselves are not uni-dimensional, but are carriers of multiple, rival norms, and modes of interpretation and action. The conceptualization of agency we use is based on the plurality of the individual, as we explain next.

\section{AGENCY IN CONTEXTS OF HYBRID ACCOUNTABILITY}

The seminal article by Emirbayer and Mische (1998) defines agency in both social-relational and temporal terms. Agency is:

...a temporally embedded process of social engagement, informed by the past (in its

'iterational' or 'habitual' aspect) but also oriented towards the future (as a projective 
capacity to imagine alternative possibilities) and toward the present (as a 'practicalevaluative' capacity to contextualize past habits and future projects within the contingencies of the moment). (p. 961)

This conceptualization of temporality is situational and plastic: past habits and routines, imaginings of future situations and a grasp of the complex practicalities of present concrete arrangements are all simultaneously available to actors. Specific social-relational contexts have implicit scripts guiding actors along pre-existing pathways, but unfamiliar or problematic situations that appear intractable by iterative approaches call for conscious deliberation. Although their concern is primarily with modalities of temporal engagement, Emirbayer and Mische (1998) close with the proposition that actors in complex relational settings may develop greater capacities for projectivity and practical-evaluation. Such settings cultivate actors' capacities for open-mindedness to diverse positions, communication, negotiation, and compromise. Delbridge and Edwards' (2013) Critical Realist evaluation of the inhabited institutions approach similarly underscores the importance of personal history and biography in shaping the actor's capacity for reflexivity.

Other scholars have taken the social-relational context as the starting point for analysing agency, arguing that agency forms are profoundly socially constructed and historically variable (Meyer and Jepperson, 2000; Abdelnour et al 2017). Abdelnour et al (2017) refer to institutions as 'patchworks' to call attention to the fact that they are made from a hotchpotch of different fabrics, stitched together and unstitched dynamically over time. Abdelnour et al (2017) argue that individuals become actors only when they take up the social roles and positions embedded within this fabric, and consequently, individuals too are patchworks. Drawing on the insight of Gellner (1994), they indicate that modern people are 'modular', 
able to compartmentalize themselves into relatively discrete packages of thought and action, accomplished at switching between them, and consequently flexible, multi-skilled and open to change.

Meyer and Jepperson (2000) similarly consider the construction of modern actorhood as a historical process. As a consequence of the progressive draining of agency formerly attributed to nature and religious gods into the individual citizen, modern actors are 'complexly structured' (p.112). With ease, they can become 'authorized agents' by shifting from agency for the self to acting or advocating on behalf of other actors and indeed abstract principles (such as 'equality'). As Meyer and Jepperson (2000) write: 'In an instant modern actors transform into others: they brim with rule-laden and intendedly thoughtful counsel for each other' (p.113). In parallel, Swidler (1986) defines 'culture' as a mixed toolkit of symbols, stories and rituals enabling people to construct 'strategies of action, persistent ways of ordering action through time' (p. 273). As Swidler (1986) emphasizes, people do not invent such strategies de novo, but construct them from pre-existing routines.

In summary, Binder (2007) attributes the creative responses she observed to the way informants 'combine and generate practices that are intended to satisfy multiple demands, [...] in interaction with others' (p. 549). We contend that the experience of multiple accountability demands, some of which may conflict, others of which may potentially be reconciled, creates the conditions in which habitual responses become conscious, may be questioned and where the potential for transformative action may reside. These contexts also provide an extensive toolkit which 'modular' individuals use to negotiate, create alliances, resist, accept defeat, try things out, or conduct smooth business-as-usual. We now describe the research site which allows us to explore these processes in greater depth. 


\section{RESEARCH DESIGN}

\section{Empirical setting}

Third sector organizations based in England and Wales and providing services for people with learning difficulties are the empirical setting for this study. Such organizations are located in a nexus of multiple and sometimes conflicting accountabilities that have been intensified by public sector reforms. First, an additional accountability relationship has been created as central government has established 'arm's length', quasi-independent regulatory bodies. Organizations are thus accountable not only to the commissioning body but also to the Care Quality Commission (CQC) whose role is to 'register, monitor, inspect and rate' services and to 'take action to protect people who are service users' (www.cqc.org.uk), remits which are overlapping, although institutionalized as discrete. These are 'core' accountability relationships (Mulgan 2000) and mediated primarily through external scrutiny, justification, sanctions and control.

In both England and Wales, the processes for designing and tendering contracts have become increasingly prescriptive and output-driven, with an emphasis on tasks ${ }^{3}$. This creates a tension, because the field of learning difficulty services is strongly influenced by the idea of an 'ordinary life' which functions as an ideology in the sense that Swidler (1986) suggests: an 'explicit, articulated, highly organized meaning system... aspiring to offer a unified answer to problems of social action' (p. 279-280). Originating primarily in the US, the idea that people with learning difficulties should be supported to lead an 'ordinary life' accompanied the policy shift from long stay institutions to community-based care. ${ }^{4}$ Towell, who authored the eponymous Kings Fund report in 1988, wrote: 
We want to see people with learning disabilities [sic] 'in the mainstream of life, living in ordinary houses and ordinary streets, with the same range of choices as any citizen, and mixing as equals with the other members [....] of their own community. (Towell 1988, cited by the Centre for Welfare Reform: online)

This commitment shifts the focus of service delivery from the tasks involved in providing care to enabling the formation of long term, meaningful relationships, and on helping people to become more independent: even if someone will always need some paid support, workers are expected to find opportunities for them to exercise as much choice as possible over how they live their lives. The 'ordinary life' functions in several ways: it provides a heuristic in shaping service quality and resolving day-to-day dilemmas; and as a professional norm which can form the basis for external scrutiny but also for personal conscience and 'expanded' (Mulgan 2000) or 'self-imposed' (Koop 2014) accountability.

\section{Fieldwork}

Nine organizations participated in the Transitions initiative, seven based in England and two in Wales. All fulfilled the five conditions specified by Koop (2014) for high levels of selfimposed accountability: supporting people with learning difficulties is always likely to attract significant attention when service failures come to light; they are direct service providers; they rely ultimately on taxpayer funding; they have a hybrid legal status in the sense that although they are not statutory organizations, they are granted authority by them; and they are relatively ‘young' organizations (being between 10-20 years old), and so cannot presume a high level of public trust. Table 1 summarizes these accountability relationships, drawing on Mulgan's (2000) and Koop's (2014) frameworks. 
Insert Table One here

The Transitions initiative was designed as an action research project aiming to bring people together to identify barriers to the provision of person-centred services, and to develop and pilot possible solutions. 'Action research' refers to a variety of approaches. Cassell and Johnston's (2006) typology identifies differing underlying ontological positions which in turn suggest different roles for the researchers, viz a viz the research subjects, alongside differing aims of the research, from more functionalist to emancipatory. Eden and Huxham (1996) suggested twelve conditions that action research should fulfil to demonstrate rigour, under the themes of 1) generality and theory generation, 2) pragmatic focus 3) research design and 4) validity. However, these twelve conditions will be answered differently depending on the underlying positions that Cassell and Johnson identify. Within their typology our study is located in the inductive/interpretive approach, in which organizational change is the desired outcome. Theory was generated from the data produced, both in the workshops amongst participants, and through the projects developed and piloted by each organization and reflected on in subsequent workshops. Participants were attracted to this initiative because of an express desire to identify and challenge barriers to good practice; thus while their intentions could be construed as implicitly critical, where such barriers were discovered to be systemic and politically imbricated, the primary motivation was to develop and pilot new approaches. The researcher and Transitions staff met regularly between sessions to reflect, share ideas about emerging themes and plan the following workshops. Emergent themes were shared with participants in the workshops and modified and refined in dialogue. Emirbayer and Mische (1998) note that 'actors who feel blocked in encountering problematic situations [the focus of the initiative] can actually be pioneers in exploring and reconstructing contexts of action' (p. 1009). Thus, the initiative presented participants with the opportunity to 'switch 
frames' (Emirbayer and Mische 1998 p.1008) away from unquestioning and iterative responses and to develop more projective and pragmatic orientations.

Organizations fielded teams of up to four participants, with between 18 and 25 people in total attending each of the five workshops that ran from November 2015 until February 2017. Christina negotiated permission to observe the workshops and to interview the lead participant in each organization, both at the beginning of the initiative and on its completion. At the outset, all lead participants were working as chief executives, project managers or with organization-wide portfolio responsibilities such as quality or inclusion. Lead participants were chosen for interviewing because there was greater continuity in their attendance, with additional team members coming and going throughout the initiative (although, as will be shown, even amongst the lead participants there was significant turnover). In Kraatz and Block's (2008) terms, interviewees were those 'responsible for internally settling issues that are unsettled within the broader environment' (p. 254). The data for the analysis below were taken from these interviews. Interview questions were open-ended and focused on participants' reflections on the obstacles to the provision of person-centred support and their strategies for dealing with them.

All participants were working under conditions of constant organizational 'churn'. For example, during the period the initiative ran, one organization tendered successfully for new contracts, leading to a rapid expansion, and another lost tenders and had to make significant cuts. Impacts on participants included redeployment, redundancy and periods of sickness absence. It is clear that these managers are working in rapidly changing and high-risk situations; risky not only in terms of their own employment but also for the service itself and those who rely on it for essential needs. For this reason, although all the lead participants 
were initially happy to be interviewed, only six of the nine were in post and available to be interviewed at the initial stage and four at the end of the project (see Table Two below). Only one from the two participating Welsh organizations was included in this analysis, the other having been made redundant during the initiative.

Insert table two here

Analysis

Coding was undertaken by both authors working independently and together as an 'insider/outsider pair' (Lingard et al 2007), enabling us to share emic understanding of, and critically reflect on, the data. An early observation was that the majority of participants' accounts encompassed references to multiple accountability relationships and it was not possible to code data on the basis of single accountabilities without destroying their meaning. Accountabilities were also described in ways that showed that they were not simple exchange relationships, but multi-stranded and dynamic. Consequently, first-order codes captured the specific accountability relationships present in informants' accounts, and their orientations towards them, using informant-centric terms. Second-order coding analysed how informants made sense of these combinations of relationships in researcher-centric terms (Eisenhardt et al 2016). We identified a range of possible responses in which single accountabilities were simply enacted; and multiple relationships were reconciled (presented as if harmoniously aligned); traded off in pursuit of resistance, which could be overt or covert; or actively elicited and used together to build coalitions of interest.

Table 3 summarizes how we moved from data to theoretical concepts, with exemplar extracts of data and codes developed from them. 
Insert Table 3 here

\section{RESPONDING TO HYBRID ACCOUNTABILITIES}

Below we present our analysis of the ways in which managers negotiated the multiple accountability demands they encountered in a variety of day-to-day situations. We highlight how they make 'trade offs' and settlements between their accountability to the ordinary life ideology and the sometimes competing, at other times overlapping requirements of internal and external stakeholders. We have identified the following categories of responses: mobilizing agency by enacting, reconciling and resisting (often through negotiation and coalition building) accountability demands; moving from iterative agency, where routine demands can be reconciled, to more complex situations that pushed managers into more deliberative modes (predictive and pragmatic).

\section{Enacting}

We understand 'enacting' accountability as using agency that Emirbayer and Mische (1998) would term 'iterational' or 'habitual': demands are made but they are seen as legitimate and conflict is minimized. We found comparatively few examples of enacting demands, probably because such instances are seen as relatively unproblematic, and hence, do not provoke much conscious reflection except in conjunction with some greater concern. For example, although all participants discussed the impact of diminishing resources, as financial pressures forced commissioners to reduce the hours for support specified within the contracts, they did not see these demands as necessarily incompatible with those of the ordinary life. As Manager 1 pointed out: 
The service has been pared back but it hasn't been to the disadvantage of the person. They've actually been able to grow in their independence ... it's been quite surprising how much more this person can do.

Manager 1 sees an integration of demands, everyone shares the commitment to good services; indeed, the pressures exerted by the new reforms lead to better services because the cuts have forced them to be more creative and the users of the service to become more independent.

\section{Reconciling}

In many more instances managers actively sought to reconcile demands that might, initially, appear to be in conflict. Below, Manager 2 demonstrates that accountability to the principles of the ordinary life ideology and its internal logic of supporting relationship-building and self-determination can be reconciled with a more task-based approach, but that this requires constant attention; such reconciliation may become habitual but only through conscious vigilance. She stresses to staff that:

...your job is to have a relationship with the people that you support [...]. The things that you do when you're here, like helping someone have a shower or a bath, going swimming, that's how you build the relationship, because you spend time hanging out with people, meeting their family and friends. But actually, what we are asking you to do all the time is focus on, and build, a good relationship. 
Manager 3 acknowledged that supporting people to be more independent might require more time, but she regarded it as her role to 'give staff permission', telling them that 'if it takes you 50 minutes to do something involving the person, and 30 minutes just doing it, then take 50 minutes'.

Tasks are, therefore, framed not as ends in themselves, but as means to relationship-building and self-determination. Accountabilities to the ordinary life and to the tasks specified in the contracts can be reconciled, but only by saying that what you are really doing is something else.

However, Manager 4 found herself in more open conflict with a commissioning social worker who wanted Manager 4's staff to be accountable to him for what tasks were being done by providing evidence in the form of a log for each service user. In Manager 4's account, '[he] told the staff that he wanted them to get a notebook folder for each individual and write down on a day to day basis, all the individual things they did'.

Manager 4's response was firm: 'I said no, we're not doing that. The commissioners cannot tell us how to record the information. They can tell us what they want, they can't tell us how to do it. And it's for us to develop the service and to show to them that we are meeting the outcomes that they want'.

In this case, the accountabilities overtly conflict. Manager 4 is accountable to the commissioning social worker for 'outcomes'. She is also accountable to her staff and to her own standards of professional and managerial authority - that it is her role to determine how time is used and tasks are achieved. In her response she demonstrates a creative fusing of 
what Emirbayer and Mische (1998) describe as the pragmatic (how to support her staff in the present moment) and future orientated scenarios (what will change). On initial reading her response could be categorized as 'resisting' but her emphasis on outcomes suggests that she is also reconciling the social worker's demands with her own by invoking a future in which the mutually agreed outcomes have been met.

Our next example also presents a tussle for authority, played out over whose interpretation of the 'ordinary life' counts, and focused on a mundane object, a whiteboard. Manager 5 runs a small group home for six young people, some of whom exhibit challenging behaviour, including two who do not communicate well verbally when they are feeling anxious. They do, however, respond well to written words or pictures; 'so we had a chat with everyone in the house, and they thought [a] whiteboard was a great idea, [...] and since the whiteboard's gone up we can write things on it without getting into conversation with that person, it stops the whole thing [anxiety] completely'.

However, the commissioners were not happy; to them, the presence of the whiteboard made the group home appear like an institution. As Manager 5 indicated, 'they really didn't like the whiteboard. They wanted it taken down because it wasn't ordinary life and you shouldn't have things like that up'. But Manager 5 resisted their demands to take it down because 'it works really well, it has a really positive effect, everybody wants it up, it's their house. So we kept it up'.

In this example, Manager 5 and the commissioners are each motivated by the desire to create an 'ordinary life' for the residents, but there is conflict over how it should be interpreted and who decides. Is it best served by ensuring that the living room looks like any other in the 
street (with no whiteboard), or by respecting the service users' rights to self-determination 'they thought the whiteboard was a great idea'? And how should accountability to the service users with anxiety be managed? Manager 5 suggests that it is the service users' interpretation that should matter, while presenting it as congruent with her own. As in the previous example, Manager 5 aims to reconcile competing claims by attempting to demonstrate that the conflict is only apparent; underneath it is a shared commitment to the principles of ordinary life and service user self-determination.

Resisting through negotiation

Our next examples differ from the ones presented above, because in these, no easy reconciliation seems possible, putting managers in a position where they have to assemble a hotchpotch of rationales and resources; but with different outcomes.

Two managers described similar situations in which they were faced with demands from commissioning social workers to accept people into their service for whom they judged it inappropriate. Manager 3 runs a respite service, and she related her concerns about a rereferral:

... it just wasn't the right place for him, and it was leading us to restrain him. Which is something we don't want to do. And the pressure from the local authority to say, well you know what? Just do it, because it's in his best interests and the family need a break. But this gentleman is not happy here, this is not the right place for him. [...] He needed a much smaller, one-to-one service. And I understand that financially it's not easy, but he was just an extremely unhappy young man. So, so difficult. But again, we had the backing from the Chief Executive to do that. 
With her CEO's support Manager 3 successfully resisted the commissioning social worker's demands. Manager 5 in contrast had eventually been forced to offer a place to a young man even though the other residents did not want to share their home with him. She similarly described the pressure as relentless; 'it went on for a long time, and we kept bouncing it to social services, they kept bouncing it back'. This resistance was unsuccessful; the social worker's wishes prevailed, but the outcome was 'huge conflict' and 'increased anxiety for everyone'.

Above, the managers are caught between multiple lines of accountability. Managers 3 and 5 are accountable to commissioners and to service users (those currently living in the house, and the people being referred). As managers they are accountable to their own staff, who will have to work with the increased stress and anxiety, and, in the first example, having previously had to perform restraint. All of these conflicting accountability demands provide resources to deploy in the dialectical (Black 2008) negotiations in which the needs of service users, the people being referred (also entitled to an ordinary life), families, commissioners and the ideals of the ordinary life jostle with each other. But the commissioners are similarly enmeshed, knowing there are vacancies in these services. Although managers framed these situations as negotiations, that they had 'won' or 'lost', the possibility of reconciliation (presumably by the commissioning social workers finding alternative, more appropriate services for the young people being referred) seems not to have been available.

\section{Resistance through building coalitions}

The final example we discuss presents overt conflict between different lines of accountability but in this case, located within one individual. In Manager 6's organization, service users can 
be elected as trustees of the governing board. One such trustee is Peter, who lives in a service which was being re-tendered. Peter expressed anxiety about the possible loss of his service; 'he came here for a Board meeting and he said, 'they can't make me go to another provider, can they?'.

Manager 6 is legally accountable to Peter because he is a member of the Board. In this context, Peter is her manager, but he is simultaneously a user of the service, and additionally, a person in some distress. Manager 4 has thus to craft a response that balances governance accountability, management accountability and advocacy accountability. The option of combining her advocacy accountability with her managerial accountability is not easily available to her because, within the market logics of the contracting process, passing on information about Peter's distress might be seen as the organization acting with a vested interest rather than as an advocate (as highlighted in the 1993 Centris Report). So, while outwardly seeming to accept the decision, Manager 6 and her staff put Peter and his fellow service users in touch with another advocacy organization which supported them to make their own case directly to the commissioning authority. The service users demanded their right to personalized budgets, so they could 'purchase' the service they wanted. Manager 6 was then able to reassure Peter: 'I said no, they've told you they're prepared to give personalized budgets and you can choose who you use that personal budget with to provide your service. Peter, and his fellow service users, then said 'good, we'll use [Manager 6's organization] to provide our services'.

Above we have presented several situations in which conflicting accountability demands mean that iterative courses of action are not sufficient. New responses need to be crafted out of available resources, including 'prefabricated' routines (Swidler 1998) borrowed from other 
accountabilities. Our managers share Binder's (2007) creativity and skill but they also deploy the resource of the 'ordinary life' to evaluate future scenarios and make judgments about how to work things out pragmatically in the here and now. These resources are deployed creatively and situationally. For example, Manager 2 resists demands to reduce hours/costs by telling her staff to take more time to teach a service user how to do a task rather than doing it for them more quickly, but Manager 1 acknowledges that in her case, the pressure to reduce demands led to greater autonomy for the services user. Although initially these two examples would seem contradictory, they are not. Here, the public sector reform goal of efficiency, and the goal of self-determination for people with learning difficulties are not in a dialectical conflict but can be reconciled.

\section{DISCUSSION}

Third sector organizations are part of highly diverse, pluralistic, 'patchworked' institutional arrangements, where newer accountability relationships concomitant with public sector reforms have brought increased complexity. Managers are charged with satisfying multiple accountability demands and have 'no choice but to choose' (Kraatz and Block 2008 p. 263). Our analysis has drawn on Emirbayer and Mische's (1988) conceptualization of agency to explore how they make sense of the choices they have made within this context.

First, our study reveals more about how the hybridity within this sector is manifested. We have observed the predicted tensions between the organizational roles of advocacy and service provision (Knight 1993), demonstrated most starkly in the example of Manager 6's response to Peter. We have also seen that organizational mission (the provision of an 'ordinary life') is deployed, as Ebrahim (2003) suggested, to strengthen the sense of distinctiveness (as in Manager 4's response to the social worker who wanted more 
documentation). However, our study also demonstrates that hybridity is not only evident in the multiple accountabilities which we categorized as 'mandatory' and 'self-imposed' (Koop 2014), and 'core' and 'expanded' (Mulgan 2000); every relationship is itself hybrid. A relationship with one person can deliver multiple accountabilities (as we saw with Peter) when this individual is simultaneously the incumbent of several roles. Managers' jobs are also comprised of multiple roles; they manage both internal and external relationships and provide a buffer when these demands conflict. External agents are also complexly structured; families can be resources to be enlisted in coalition-building, and they can also be resisted when they are judged to constrain service users' choices. Social workers and commissioners demand contract compliance yet are also juggling demands from families and users, and trying to make diminishing resources stretch. Service users may be the primary source of accountability but when the needs of different service users conflict (as in the examples of referrals deemed 'inappropriate') then choices must be made.

Thus, our work extends Binder's (2007) study, also located in the non-profit sector. Our findings support her conclusion that staff are highly resourceful and inventive. However, unlike Binder's, our managers were sufficiently senior that they had to maintain an overview of the entire organization as well as the competing demands from external stakeholders; the option of 'segmenting' responses (Skelcher and Smith 2015) that Binder observed, was not available to them.

Secondly, our analysis explores the choices managers make to enact, reconcile or resist such hybrid accountability. Whenever possible, managers sought to reconcile demands. This may be a consequence of our research design; the emphasis on problematic situations inevitably meant that there was less discussion of demands that could be enacted unproblematically 
using iterative responses (Emirbayer and Mische 1998). However, the examples of what appear as straightforward enacting that we observed (in Table 3 as well as at the beginning of the findings) suggest that this is better understood as implicit reconciling; the demands of one particular relationship presumed to fit in with the unspoken demands of all the other accountability relationships that are simultaneously present in the background.

Therefore, it is those situations that provoked disquiet, where demands cannot easily be met, that are the focus of our managers' discussions. In seeking reconciliation managers drew on a repertoire of resources, combining pragmatic responses with future imaginings in which options were judged and taken up or discarded in terms of the extent to which they were likely to promote an ordinary life. Ultimately, decisions were justified in terms of the needs of specific service users but these were defined in differing ways (as 'compromise' in the service for nine residents or 'reducing anxiety' in the case of the whiteboard). Thus, while the ordinary life provided a foundational heuristic in future imaginings, it was also variously invoked to justify excluding a young man whose needs were deemed to be irreconcilable with the existing residents, to reduce the number of hours one service user received, or increase the time spent with another.

Overt resistance to accountability demands was rare. We found no examples of resistance to the CQC's demands. Resistance to commissioners' demands were primarily enacted, as Emirbayer and Mische (1988) suggest, by being 'seized on the wing ... [which] requires shrewdness, tact and situational awareness' (p.1000-1001). In one case an appearance of resistance was described (resisting demands for staff to document their actions) but this was done through appealing to shared outcomes. In other examples, when demands could not be reconciled (Peter's desire to stay with Manager 6's organization) resistance was covert and 
enacted through building coalitions (increasing the hybridity of actors involved) or by manoeuvring and negotiation. Resistance was thus avoided unless there was a perceived threat to particular users' interests (the young man who had been restrained) but these are not fixed or absolute. Thus, we can predict that the primary response to conflicting accountability demands is likely to be to try to reconcile them through an appeal to self-imposed understandings of organizational mission, as expressed through the needs of service users, even if this requires compromise and distortion.

Thirdly, we analysed how managers made these choices. As Kraatz and Block (2008) argue, plurality is not only external to the organization, but is 'constitutive and ideational; $[. .$. suffusing the organization' (p. 244). While the managers we studied are themselves plural, their superordinate espoused aim is to act as authorized agents (Meyer and Jepperson 2000) for their service users. They devise, adapt, and deploy action strategies which can then be laid down for future iteration (Swidler 1986): the approach tried out with one local authority commissioner can then be re-used with another. The ordinary life is itself a sort of rubric that can be enacted and tweaked in situ. Managers are modular, in Gellner's terms (1994), able to separate out the strands tangled up within situations, and openminded to new interpretations such as that by reducing a support package, the service can improve because the independence of the service user is increased. Managers demonstrated a propensity towards viewing external stakeholders in a variety of ways; families as a source support in one case and constraint in others. The complex interactions between these relationships produce new demands and simultaneously offer resources to managers.

Our study, of an organisational setting where hybridity is intense, adds to understanding of settings where plurality is experienced more moderately. Research into settings where the 
institutional environment was until recently experienced as singular or intact, have shown that the intrusion of new institutional logics allows actors to take up new identities (e.g. Meyer et al 2014; McGivern et al 2015). 'Nested' identities are held together with a 'cross cutting' identity carrying deeply held professional ideals, which is brought to bear across a range of situations (Spyridonidis et al 2015 p. 396). Similarly, we find that the 'ordinary life' is used as a yardstick across practically all problematic situations that managers encounter, but it too is multi-faceted, negotiable, and may implicitly be revoked in some circumstances. Goodrick and Reay's (2011) historical study of the pharmacy profession indicates that multiple logics that could not be easily reconciled were 'segmented' into different organisational functions or into separate activities within the job role. In the third sector setting we studied, segmentation was not possible, either within the organisation or the managerial role. Rather, managers used temporal segregation; a settlement reached in one situation may be fleeting and may differ from the next. Like our study, McPherson and Sauder (2013) show that professional logics provide a toolkit that is to some extent accessible to members of all the different professions involved, who combine them creatively in situ in pursuit of diverse aims. What our study adds to these is in our elucidation of the far-reaching hybridity of the third sector and the complex forms of actorhood this cultivates, able to handle resources with great dexterity, in pursuit of settlements which may only be temporary, and anchored by their commitment to supporting an 'ordinary life'.

\section{REFERENCES}

Abdelnour, S., Hasselbladh, H., \& Kallinikos, J. 2017. 'Agency and institutions in organization studies', Organization Studies, 38, 1775-1792 doi: 0170840617708007. 
Benish, A., \& Levi-Faur, D. 2012. 'New forms of administrative law in the age of thirdparty government'. Public Administration, 90(4), 886-900. doi: 10.1111/j.14679299.2012.02037.x

Billis, D. 2010. Towards a theory of hybrid organizations, in Hybrid Organizations and the Third Sector D. Billis (ed.) Basingstoke: Palgrave: 46-69

Binder, A. 2007. For love and money: Organizations' creative responses to multiple environmental logics. Theory and society, 36(6), 547-571. DOI 10.1007/s11186-007-9045$\mathrm{X}$

Black, J. 2008. Constructing and contesting legitimacy and accountability in polycentric regulatory regimes. Regulation and Government 2: 137-164. doi:10.1111/j.17485991.2008.00034.x

Bovens, M. 2007. Analysing and assessing accountability: A conceptual framework. European Law journal, 13(4), 447-468. doi: 10.1111/j.14680386.2007.00378.x

Brandsen, T.W., van de Donk, W., and Putters, K. 2005. Griffins or chameleons? Hybridity as a permanent and inevitable characteristic of the third sector', International Journal of Public Administration, 28, 9-10, 749-65. DOI: 10.1081/PAD-200067320

Cassell, C. and Johnson, P. 2006. Action research: Explaining the diversity. Human Relations 783-814. doi:10.1177/0018726706067080 
Castellas, E. I., Stubbs, W., \& Ambrosini, V. 2018. Responding to value pluralism in hybrid organizations. Journal of Business Ethics, 1-16. doi:10.1007/s10551-018-3809-2

Delbridge, R., \& Edwards, T. 2013. Inhabiting institutions: Critical realist refinements to understanding institutional complexity and change. Organization Studies, 34(7), 927-947. DOI: $10.1177 / 0170840613483805$

Denis, J. L., Ferlie, E., \& Van Gestel, N. 2015.'Understanding hybridity in public organizations. Public Administration, 93, 273-289 doi: 10.1111/padm12175

Doheny, S. 2015. The Organization of the NHS in the UK: Comparing structures in the four countries Research paper commissioned by the National Assembly of Wales

Ebrahim, A. 2003. 'Making sense of accountability: Conceptual perspectives from northern and southern non-profits', Nonprofit Management and Leadership 14, 191-212 doi:10.1002/nml.2077

Ebrahim, A., Battilana, J., \& Mair, J. 2014. The governance of social enterprises: Mission drift and accountability challenges in hybrid organizations. Research in Organizational Behavior, 34, 81-100. doi: 10.1016/j.riob.2014.09.001

Eden, C. and Huxham, C., 1996. Action research for management research. British Journal of Management. 75-86. doi10.1111/j.1467-8551.1996.tb001/07 
Eisenhardt, K. M., Graebner, M. E., \& Sonensheim, S. 2016. From the editors: Grand challenges and inductive methods: Rigor Without Rigor Mortis'. Academy of Management Journal, 59(4): 1113-1123.

Emirbayer, M., \& Mische, A. 1998. 'What is agency?'. American Journal of Sociology, 103(4), 962-1023.

Fine, G. A., \& Hallett, T. 2014. 'Group cultures and the everyday life of organizations: Interaction orders and meso-analysis'. Organization Studies, 35(12), 1773-1792.

Gellner, E. 1994. Conditions of liberty: Civil society and its rivals. Hamish Hamilton Ltd.

Goodrick, E., \& Reay, T. 2011. 'Constellations of institutional logics: Changes in the professional work of pharmacists'. Work and Occupations, 38(3), 372-416. DOI: $10.1177 / 0730888411406824$

Knight, B. 1993. Voluntary action. London: Centris

Koop, C. 2014. 'Theorizing and explaining voluntary accountability'. Public Administration, 92: 565-581 doi:10.1111/padm.12058

Kraatz. M.S. and Block, E. 2008. 'Organizational implications of institutional pluralism' (p. 243-275) R. Greenwood, C. Oliver, K. Shalin and R. Suddaby (eds.) The Sage Handbook of Organizational Institutionalism. Los Angeles: Sage. 
Lingard, L., Schryer, C.F., Spafford, M.M., \& Campbell, S.L. 2007. 'Negotiating the politics of identity in an interdisciplinary research team'. Qualitative Research, 7(4), 501519. DOI: $10.1177 / 1468794107082305$

McGivern, G., Currie, G., Ferlie, E., Fitzgerald, L., \& Waring, J. 2015. Hybrid managerprofessionals' identity work: The maintenance and hybridization of medical professionalism in managerial contexts. Public Administration, 93, 412-432 doi: 10.1111/padm.12119

McKay, S., Moro, D., Teasdale, S. and Clifford, D. 2011. The Marketization of Charities in England and Wales Working paper 69: Third Sector Research Centre, Universities of Birmingham and Southampton

McPherson, C.M. and Sauder, M., 2013. 'Logics in action: Managing institutional complexity in a drug court'. Administrative Science Quarterly, 58(2), 165-196.

Meyer, J. W., \& Jepperson, R. L. 2000. 'The 'actors' of modern society: The cultural construction of social agency', Sociological theory, 18(1), 100-120.

Meyer, R. E., Egger-Peitler, E., Höllerer, M. A., \& Hammerschmid, G. 2014. Of bureaucrats and passionate public managers: Institutional logics, executive identities, and public service motivation. Public Administration, 92(4, 861-885. doi: 10.1111/j.14679299.2012.02105.x

Mulgan, R. 2000. 'Accountability': An ever-expanding concept? Public 
Administration, 78, 555-573 doi10.1111/14567-9299.11218

National Coalition for Independent Action, 2015. Fight or Flight? A Summary of the Inquiry Findings. Available at:

http://www.independentaction.net/wp-content/uploads/sites/8/2015/02/NCIA-Inquirysummary-report-final.pdf

Ospina, S., Diaz, W., \& O’Sullivan, J. F. 2002. 'Negotiating accountability: Managerial lessons from identity-based nonprofit organizations'. Nonprofit and voluntary sector quarterly, 31(1), 5-31. doi: 10.1177/0899764002311001

Pollitt, C. \& G. Bouckaert. 2011. Public Management Reform: A Comparative Analysis New Public Management, Governance, and the Neo-Weberian State, 3rd edn. Oxford: Oxford University Press.

Sanders, M. L., \& McClellan, J. G. 2014. 'Being business-like while pursuing a social mission: Acknowledging the inherent tensions in US nonprofit organizing'. Organization, 21(1), 68-89. DOI: 10.1177/1350508412464894

Schwabenland, C. 2016 Stories, Visions and Values in Voluntary Organisations London: Routledge

Skelcher, C., \& Smith, S. R. 2015. 'Theorizing hybridity: Institutional logics, complex organizations, and actor identities: The case of nonprofits'. Public Administration, 93, 433448 doi:10.1111/padm.12105 
Spyridonidis, D., Hendy, J., \& Barlow, J. 2015. 'Understanding hybrid roles: The role of identity processes amongst physicians'. Public Administration, 93, 395-411: doi:10.1111/padm.12114

Swidler, A. 1986. 'Culture in action: Symbols and strategies'. American Sociological Review, 273-286.

Towell, D. 1988. An Ordinary Life in Practice: developing comprehensive community based services for people with learning disabilities London: Kings Fund: cited by the Centre for Welfare Reform:

http://www.centreforwelfarereform.org/uploads/attachment/362/delivering-the-promise-ofan-ordinary-life.pdf: accessed 28/10/16 
Table 1: Accountability relationships in third sector organizations providing services to people with learning difficulties

\begin{tabular}{|c|c|c|c|}
\hline Accountability to: & For: & $\begin{array}{l}\text { Core or } \\
\text { Expanded } \\
\text { (Mulgan, 2000) }\end{array}$ & $\begin{array}{l}\text { Mandatory or } \\
\text { Self-Imposed } \\
\text { (Koop, 2014) }\end{array}$ \\
\hline $\begin{array}{l}\text { Local authority } \\
\text { commissioners }\end{array}$ & Contract compliance & Core & Mandatory \\
\hline $\begin{array}{l}\text { Care Quality } \\
\text { Commission }\end{array}$ & Regulatory compliance & Core & Mandatory \\
\hline Professional bodies & $\begin{array}{l}\text { Adherence to standards } \\
\text { for professional practice }\end{array}$ & Core & Mandatory \\
\hline $\begin{array}{l}\text { Governing Board of } \\
\text { Trustees }\end{array}$ & $\begin{array}{l}\text { Executive staff } \\
\text { responsible for delivering } \\
\text { organization's vision and } \\
\text { purpose }\end{array}$ & Core & Mandatory \\
\hline $\begin{array}{l}\text { Personal accountability } \\
\text { to 'Ordinary Life' }\end{array}$ & $\begin{array}{l}\text { Embedding it in personal } \\
\text { practice }\end{array}$ & Expanded & Self-imposed \\
\hline Advocacy groups & $\begin{array}{l}\text { Networking, working co- } \\
\text { operatively, shared }\end{array}$ & Expanded & Self-imposed \\
\hline
\end{tabular}




\begin{tabular}{|l|l|l|l|}
\hline & advocacy or campaigning & & \\
\hline Service users & $\begin{array}{l}\text { Provision of services and } \\
\text { involvement in decision } \\
\text { making }\end{array}$ & Core and & Mandatory and \\
or guardians & $\begin{array}{l}\text { Consultation, } \\
\text { involvement, advocacy }\end{array}$ & expanded & self-imposed \\
\hline The public & $\begin{array}{l}\text { Using public funds } \\
\text { appropriately, upholding } \\
\text { high standards of }\end{array}$ & Expanded & Self-imposed \\
& transparency and probity & & \\
\hline
\end{tabular}


Table 2: Participants included in this article

\begin{tabular}{|c|c|c|c|c|}
\hline Participant & Role & $\begin{array}{l}\text { Size of } \\
\text { organization }\end{array}$ & $\begin{array}{l}\text { Local, regional } \\
\text { or national }\end{array}$ & $\begin{array}{l}\text { Interviewed } \\
\text { at start and / } \\
\text { or finish of } \\
\text { project }\end{array}$ \\
\hline Manager 1 & Senior manager & Large & $\begin{array}{l}\text { Regional: } \\
\text { Wales }\end{array}$ & $\begin{array}{l}\text { Beginning and } \\
\text { end }\end{array}$ \\
\hline Manager 2 & Co-director & Small & $\begin{array}{l}\text { Local: } \\
\text { England }\end{array}$ & $\begin{array}{l}\text { Beginning and } \\
\text { end }\end{array}$ \\
\hline Manager 3 & Senior manager & Large & $\begin{array}{l}\text { National: } \\
\text { England }\end{array}$ & $\begin{array}{l}\text { Beginning and } \\
\text { end }\end{array}$ \\
\hline Manager 4 & Senior manager & Medium & $\begin{array}{l}\text { Regional: } \\
\text { England }\end{array}$ & $\begin{array}{l}\text { Beginning and } \\
\text { end }\end{array}$ \\
\hline Manager 5 & Project manager & Medium & $\begin{array}{l}\text { Regional: } \\
\text { England }\end{array}$ & $\begin{array}{l}\text { Beginning } \\
\text { only }\end{array}$ \\
\hline Manager 6 & Senior manager & Medium & $\begin{array}{l}\text { Regional: } \\
\text { England }\end{array}$ & $\begin{array}{l}\text { Beginning } \\
\text { only }\end{array}$ \\
\hline
\end{tabular}


Table 3: Analytical strategy

\begin{tabular}{|c|c|c|}
\hline Exemplar data & $\begin{array}{l}\text { First order } \\
\text { codes: } \\
\text { accountability } \\
\text { relationships and } \\
\text { orientations }\end{array}$ & $\begin{array}{l}\text { Second order } \\
\text { codes: } \\
\text { managing } \\
\text { multiple } \\
\text { accountability } \\
\text { relationships }\end{array}$ \\
\hline $\begin{array}{l}\text { If I can get [strategy] to work with one local } \\
\text { authority then I can learn from that, and say well, } \\
\text { they were happy until they got to that bit, so that bit } \\
\text { probably needs tweaking before I go to [another } \\
\text { local authority]. }\end{array}$ & $\begin{array}{l}\text { Commissioners: } \\
\text { trialling, refining } \\
\text { and replicating } \\
\text { strategies }\end{array}$ & Enacting \\
\hline $\begin{array}{l}\text { We've shown [the CQC] what we were doing, we've } \\
\text { explained to them why we were doing it. ... we've } \\
\text { got a range of inspectors, but on the whole it's been } \\
\text { quite good, it's been very, very good. }\end{array}$ & $\begin{array}{l}\text { Regulators: being } \\
\text { transparent }\end{array}$ & Enacting \\
\hline $\begin{array}{l}\text { I have nine people in my service. We start from an } \\
\text { individual basis about what is it that is important to } \\
\text { that person. How do they want to live their lives? } \\
\text { And then you have to compromise. But what we try }\end{array}$ & $\begin{array}{l}\text { Service users: } \\
\text { Ordinary life } \\
\text { Institutional }\end{array}$ & Reconciling \\
\hline
\end{tabular}




\begin{tabular}{|c|c|c|}
\hline $\begin{array}{l}\text { and do is minimize those compromises, and then get } \\
\text { the really important stuff right for that person. }\end{array}$ & $\begin{array}{l}\text { demand (having to } \\
\text { live with } 8 \text { other } \\
\text { people) }\end{array}$ & \\
\hline $\begin{array}{l}\text { We were asked to go down to [region], work with } 3 \\
\text { individuals with challenging behaviours who were to } \\
\text { be supported to move into the community } \\
\text { [previously there had been] a massive inquiry, a big } \\
\text { scandal. People started coming and asking us to } \\
\text { support their son or daughter, so that's how we grew } \\
\text { in [region]. But it was the first time that we were } \\
\text { being interviewed by family members. }\end{array}$ & $\begin{array}{l}\text { Regulators for } \\
\text { compliance } \\
\text { The public - } \\
\text { maintaining trust } \\
\text { Prospective } \\
\text { families - gaining } \\
\text { trust }\end{array}$ & Reconciling \\
\hline $\begin{array}{l}\text { And as long as you've been honest and open with } \\
\text { [commissioners] in the past, they'll work with you } \\
\text { [...] we'll say, 'things are going really well, perhaps } \\
\text { we can reduce this package,' or 'you know what? } \\
\text { this isn't working for this person, we're struggling } \\
\text { with this, we've tried this, this and this, we've } \\
\text { brought in external professionals, community } \\
\text { learning disability nurses, but we just need to have a } \\
\text { look at the package and reassess'. }\end{array}$ & $\begin{array}{l}\text { Commissioners: } \\
\text { being honest and } \\
\text { open; showing } \\
\text { willingness to } \\
\text { reduce some } \\
\text { packages as a way } \\
\text { of increasing } \\
\text { others; bringing in } \\
\text { external } \\
\text { professional } \\
\text { expertise to } \\
\text { justify }\end{array}$ & $\begin{array}{l}\text { Subtle } \\
\text { resistance }\end{array}$ \\
\hline When we were talking to the Members Board [they & Governing board & Resisting \\
\hline
\end{tabular}




\begin{tabular}{|c|c|c|}
\hline asked] 'have you ever been stopped from making a & of trustees: & wishes of or \\
\hline decision for yourself?' And that's quite a powerful & including them in & assumptions \\
\hline message, isn't it? So [the Members Board] did a & decision-making & of, support \\
\hline presentation about wise decisions $[\ldots]$ and they & and persuading & workers or \\
\hline showed this film. The film includes somebody going & them that service & families \\
\hline off to get a tattoo and $[\ldots]$ you have the staff & users should make & \\
\hline member going 'I can't let you do that', and the & informed choices & \\
\hline chap's going 'well actually it's not your decision and & Staff members: & \\
\hline I'm going to do that'. 'No, but you can't, I'd get in & giving them & \\
\hline trouble'. 'No you won't because it's my choice to do & permission & \\
\hline that'. The film talks through how he's actually made & Service users: & \\
\hline an informed choice, and so it's all right for him to do & entitlement to & \\
\hline that. And he says that his parents didn't want him to & make own & \\
\hline have [the tattoo] that, but he really likes it and wants & decisions & \\
\hline \multirow[t]{3}{*}{ it and he was supported to do so. } & Families: might & \\
\hline & not get what they & \\
\hline & want & \\
\hline The longer you've supported people, the longer your & Service users & Resisting \\
\hline relationship with people's families and friends and & Families & through \\
\hline the better connected the people you support are, then & Advocates & coalition- \\
\hline the more people are going to fight their corner [if & Commissioners & building \\
\hline there is a threat that the contract will be re-tendered] & & \\
\hline that's how we've chosen to protect the people. It's & & \\
\hline not protecting us, it's protecting them, their life and & & \\
\hline their service and their support. Everybody's got & & \\
\hline
\end{tabular}




\begin{tabular}{|l|l|l|}
\hline family or friends or advocates that we could call on, \\
to say 'can you make a bit of a fuss' - cause \\
obviously we've got the conflict of interest if we're \\
the person advocating for that, we've got 'oh you're \\
just the provider so it's in your interests to keep \\
them here'.
\end{tabular}

\footnotetext{
' We use the label 'people with learning difficulties' because the advocacy group People First regards it as the least worst way of categorizing the people who use the services under discussion in this article.

2 All names of organizations and participants are pseudonyms.

3 There are differences in the structures that determine and regulate contracting regimes between England and Wales, driven to some extent by the increasing devolution of powers from the UK to the four nations, including differences in the ways in which health and social care are integrated. Doheny's (2015) comparative study found that the English systems are more 'marketized' while the other nations are becoming more bureaucratized. However, these differences were not reflected in our findings.

${ }^{4}$ The introduction of new medication that could assist people with mental health conditions to 'manage' their symptoms initiated a series of policy changes aimed at supporting people within their communities rather than in long-stay 'asylums'. This led to a 'period of rapid de-institutionalization' and a continuous programme of hospital closures throughout the second part of the $20^{\text {th }}$ century, explicitly confirmed in the 1990 NHS and Community Care Act (https://www.kingsfund.org.uk/sites/default/files/field/field_publication_file/servicetransformation-lessons-mental-health-4-feb-2014.pdf)
} 